\title{
DISERTACIONES
}

NORMAS

\section{NORMAS PARA AUTORES/AS}

\section{Características de las contribuciones y artículos recibidos}

Disertaciones es una revista académica y científica, de acceso abierto en internet, que publica aportes originales y relevantes en el campo de la comunicación social, específicamente en las líneas de: (i) Sociedad y Tecnologías de la Información y la Comunicación; (ii) Comunicación y Política; (iii) Periodismo, y (iv) Comunicación y Cultura.

La revista recibe artículos escritos en español, inglés y portugués. Todos los artículos propuestos a Disertaciones deben ser de carácter inédito, por lo cual no se aceptarán trabajos que hayan sido publicados previamente, ya sea en medio impreso o en internet, o que se encuentren en proceso de evaluación en otra publicación.

El contenido de la revista está organizado en cuatro secciones: Estudios, Avances, Ensayos, Reseñas.

Disertaciones tiene como eje principal la publicación de artículos de investigación, originales e inéditos, cuyos resultados contribuyan al avance del conocimiento científico en el campo de la comunicación. Estos artículos son editados en las secciones Estudios y Avances.

La sección Estudios, de carácter monográfico, reúne los artículos especializados que aportan al dosier temático específico convocado para cada número de la revista.

La sección Avances publica artículos de tema abierto de investigación en comunicación, que aporten al conocimiento sobre las líneas temáticas generales de la revista.

En la sección Ensayos se divulgan artículos de reflexión que, derivados de experiencias de investigación o de una sólida revisión crítica de la literatura académica pertinente y actualizada, hagan una aportación original al debate teórico o metodológico sobre el tema central de cada número de la revista.

La revista también publica reseñas críticas de libros o eventos académicos destacados y recientes relacionados con los estudios en comunicación. Estos textos son editados en la sección Reseñas.

- Los artículos recibidos en Disertaciones, antes de ser enviados a pares evaluadores, serán revisados inicialmente por un equipo del consejo de redacción de la revista con el fin de verificar que cumplan efectivamente con las presentes normas para los autores. En este proceso la revista somete los manuscritos recibidos a un software que coteja el nivel de originalidad del texto y el adecuado manejo de citaciones.

\section{Parámetros de presentación de artículos (secciones Estudios, Avances, Ensayos)}

- Los artículos deberán presentarse en formato Word (.doc o .docx), escritos en fuente Times New Roman de 12 puntos, a espacio y medio, página tamaño carta con márgenes de $2,5 \mathrm{~cm}$, y paginado en el ángulo derecho superior. Las notas a pie de página, las cuales serán utilizadas solo para realizar aclaraciones per- 


\section{DISERTACIONES}

NORMAS

tinentes y comentarios adicionales al texto central, se numeran consecutivamente y escriben en fuente Times New Roman de 10 puntos. Las referencias bibliográficas irán al final del artículo, ordenadas alfabéticamente y siguiendo las normas de estilo de la Asociación Psicológica Americana (APA), en su más reciente versión (sexta en inglés, tercera en español traducida de la versión sexta en inglés).

- La extensión de los artículos (publicados en las secciones Estudios, Avances y Ensayos) será mínimo de 4000 palabras y máximo de 9000 palabras, incluyendo el resumen, notas al pie y referencias bibliográficas.

- En el contenido del artículo no se deben incluir datos o referencias que identifiquen a los autores del texto enviado. Para registrar dichos datos se debe adjuntar otro archivo en Word que contenga para cada uno de los autores: nombres y apellidos, formación académica, filiación institucional, principales líneas de investigación y dirección de correo electrónico. Asimismo, en este archivo anexo se deberá registrar la información sobre el origen del trabajo presentado: proyecto de investigación del cual se deriva el artículo, así como el crédito que corresponda a las instituciones que apoyaron la realización del proyecto.

- Cada artículo irá precedido por el título, que debe ser conciso sobre el objeto y alcance del texto, y un resumen que sintetice, en un párrafo de máximo 200 palabras, los elementos centrales del trabajo, destacando las tesis o argumentos centrales, resultados, aportes y conclusiones más relevantes. Tanto el título como el resumen deben ser presentados en el idioma original del artículo y ser traducidos al inglés (o al español si el artículo es escrito en inglés).

- Tras el resumen se deben incorporar entre tres y cinco palabras clave que permitan identificar el contenido del artículo. Igualmente, estas palabras deberán estar en el idioma original del artículo y ser traducidas al inglés (keywords), o al español si el cuerpo del trabajo está escrito en inglés.

- Los artículos de investigación, publicados en las secciones Estudios y Avances, deben estar organizados siguiendo en términos generales la estructura convencional de los trabajos científicos, particularmente en ciencias sociales: introducción, antecedentes o estado de la cuestión, metodología, resultados, discusión y conclusiones. Se espera que la estructura específica mediante la cual se desarrolla cada artículo sea apropiada y consistente con la perspectiva teórico-metodológica del estudio realizado.

- Todos los artículos deben tener secciones tituladas o subtítulos, de acuerdo con la estructura del texto. Sin embargo, la introducción del artículo no va precedida de un título que la designe como tal, pues se asume que la primera parte del manuscrito corresponde a la introducción. Para las demás secciones y subsecciones del artículo se utilizarán niveles de títulos y subtítulos, sin letras o números, dependiendo de la jerarquización de la información del trabajo. Si bien la mayoría de la estructura de los artículos de investigación tienen por lo general hasta tres niveles de títulos, la revista utiliza una adaptación del estilo APA de encabezados, que ofrece hasta cinco niveles de subordinación en el formato de los títulos: 
Tabla 1. Formato para jerarquización de niveles de títulos y subtítulos

\begin{tabular}{ccc} 
Nivel de título & Formato \\
1 & Título de sección en negritas centrado \\
2 & Subtítulo en negritas, alineado a la izquierda \\
3 & Subtítulo de párrafo con sangría y negritas \\
4 & Subtítulo de párrafo con sangría, en negritas y cursiva \\
5 & Subtítulo de párrafo con sangría y cursiva \\
\hline
\end{tabular}

Adaptado del Manual de Publicaciones de la APA, tercera edición en español traducida de la sexta versión en inglés.

Únicamente deben emplearse los niveles de título que sean necesarios según los apartados y subapartados del texto presentado. Así, el artículo podrá estructurarse solo con títulos de sección, para lo cual debe emplear solo el nivel de título 1 o podrá tener hasta 5 niveles de subsecciones y emplear para cada una de ellas los niveles de título respectivos.

- Si el artículo incluye figuras y tablas estas deben ser numeradas con números arábigos, en orden correlativo a como se mencionan en el texto. Las tablas deben entregarse incorporadas en formato de tabla de Word al mismo archivo en el que se presenta el artículo. Igualmente las figuras y fotografías deben estar incorporadas al archivo de Word, y adicionalmente adjuntarlas como archivos anexos en formato jpg. Cada tabla incorporada al artículo debe llevar un título descriptivo en la parte superior y las leyendas de las figuras deben ser lo suficientemente explicativas. Al pie de la tabla se registran las notas aclaratorias, así como el crédito a la fuente de datos. Se debe evitar la utilización de líneas verticales en las tablas, procurando presentar de la manera más clara posible los datos al lector. Para recomendaciones más detalladas de presentación de las tablas y figuras consultar el capítulo 5 del Manual de publicaciones de la APA.

- Para una exposición detallada del conjunto de datos y resultados de la investigación, ya sean cuantitativos o cualitativos, se recomienda la utilización de archivos en línea complementarios. Si el autor requiere la utilización de visualizaciones especiales para la presentación de datos, como gráficos, videos o tablas interactivas, la revista hará las gestiones para incorporar estos formatos.

- La revista sugiere a sus autores el envío del conjunto de datos en bruto de la investigación y el libro de códigos utilizado con el fin de fortalecer la rigurosidad y comunicabilidad del aporte investigativo, dando la posibilidad de la replicación y confrontación de los resultados por otros investigadores. Este envío es opcional.

- Las propuestas de artículos a Disertaciones se recibirán a través del sistema en línea de recepción de textos para evaluar por la revista, disponible en la página web: http://revistas.urosario.edu.co/index.php/ disertaciones/ 


\section{DISERTACIONES}

NORMAS

\section{Normas de estilo y citación de referencias}

En cuanto a las normas de estilo, citación y referencias bibliográficas, los artículos propuestos a la revista deben prepararse siguiendo el manual de publicaciones (en su sexta versión en inglés y tercera en español, la cual corresponde a la traducción oficial de la APA sexta versión en inglés).

Se retoma aquí una síntesis general de las normas de estilo y citación que son más comúnmente empleadas en los artículos de investigación:

- Las abreviaturas referidas a conceptos y términos técnicos se usarán solo si resultan estrictamente necesarias. Los términos abreviados, así como las siglas y acrónimos, se deben escribir completos la primera vez que aparecen e inmediatamente después como abreviatura entre paréntesis.

- Para el reporte de datos estadísticos las fórmulas solo deben utilizarse cuando estas resultan esenciales para el artículo o cuando se presenta una expresión matemática o estadística nueva, no para la presentación de un dato estadístico de uso común. Preferiblemente, las ecuaciones se deben presentar en formato editable en el procesador de palabras y no en formato de imagen. Sobre detalles específicos para la presentación de material estadístico y matemático en el artículo consultar el capítulo 4 del Manual de estilo de publicaciones APA.

- Las citas textuales y paráfrasis se deben referir en el cuerpo del texto siguiendo las normas APA (autor, año, página de la cita). Cuando se utilicen citas textuales menores de 40 palabras se incorporan directamente al texto entrecomilladas, y después de cerrar comillas se registra entre paréntesis a la fuente. Las citas textuales mayores de 40 palabras deben ir en párrafo aparte, con sangría en el margen izquierdo de 2,5 cm y sin entrecomillar. Después del signo de puntación final de la cita se debe referir la fuente entre paréntesis.

- Al final del artículo, bajo el encabezado de Referencias, se debe listar en orden alfabético únicamente la lista de referencias que realmente hayan sido utilizadas y citadas en el cuerpo del texto. Para la elaboración de las citaciones y el listado de referencias deben seguirse las normas APA, ya sea en la sexta edición en inglés o la traducción oficial al español (tercera edición), dependiendo del idioma en el cual esté escrito el artículo.

- Sobre dudas específicas de citación de las fuentes, se recomienda a los autores consultar, además de los manuales de estilo referidos, el sitio en internet de las normas de estilo APA en inglés (www.apastyle.org)

\section{Lineamientos generales para la presentación de reseñas de libros y eventos académicos}

- Las reseñas tendrán una extensión máxima de 1500 palabras y deben ser presentadas en archivo Word, siguiendo el formato de fuente, espaciado y márgenes referido en los requerimientos de presentación de artículos para la revista. En el mismo archivo se deben registrar los datos identificatorios del autor de la reseña: nombre y apellidos, filiación institucional y líneas de investigación.

- Si se trata de una reseña de libro, al final del texto se deben incluir los datos bibliográficos completos de la obra reseñada: autor, fecha, título completo, ciudad, editorial, número de páginas. Si se trata de la 
reseña de un evento académico se debe referir: nombre del evento, instituciones organizadoras, lugar y fecha de realización.

- El libro objeto de la reseña debe haber sido publicado en los dos últimos años y constituir una clara aportación a la investigación en comunicación. Si se trata de la reseña de un evento académico este debe haber sido realizado durante el último año y ser un acontecimiento de notable relevancia internacional para los estudios en comunicación. No necesariamente el libro o evento reseñado tiene que estar directamente relacionado con el monográfico del número de la revista al cual se envía la reseña.

- Quien realice la reseña propuesta a la revista no debe haber participado como editor o coautor del libro reseñado, o ser parte del comité académico del evento objeto del texto. Es recomendable que el autor de la reseña tenga una trayectoria académica reconocida en torno al tema o área específica en la que se inscribe el libro o evento referido.

- Se espera que las reseñas de libros propuestas a la revista trasciendan el plano meramente descriptivo y ofrezcan una perspectiva crítica y constructiva, que permita identificar los alcances y limitaciones de la obra, destacando la pertinencia de sus aportes al área específica en la cual se inscribe en el campo de los estudios en comunicación.

- Para citaciones directas del libro reseñado se hará referencia entre paréntesis a la página de donde se toma la cita. Para citaciones de otras obras en el cuerpo de la reseña se utilizarán las normas APA. 